\title{
Diagnóstico do sistema de gerenciamento dos resíduos sólidos urbanos do município de Passo Fundo/RS
}

\author{
Diagnosis of the municipal solid waste management \\ system in the city of Passo Fundo/RS
}

\section{Aline Pimentel Gomes | Adalberto Pandolfo | Aline Ferrão Custódio Passini Pedro Domingos Marques Prietto | Nicole Becker Portela}

Data de entrada: 10/08/2012 | Data de aprovação: 05/07/2012

Resumo

Este trabalho tem como objetivo diagnosticar o atual sistema de gerenciamento dos resíduos sólidos urbanos do município de Passo Fundo/RS. Dados referentes aos serviços de limpeza urbana e ao manejo dos resíduos sólidos foram obtidos nos órgãos públicos municipais por meio de entrevistas, análises de documentos e observações diretas. Os resultados demonstram a falta de capacitação técnica da administração pública municipal, a ausência de políticas públicas voltadas aos resíduos sólidos e a falta de conscientização da população, que não faz a separação dos recicláveis na fonte, além disso, o município não possui uma usina de compostagem, a usina de triagem existente não tem sido operada adequadamente e a situação da área de disposição final de resíduos sólidos do município é precária.

Palavras-chave: resíduos sólidos urbanos; gerenciamento de resíduos sólidos; manejo de resíduos sólidos

\begin{abstract}
The aim of this paper is to diagnose the current municipal solid waste management system in the city of Passo Fundo/RS. Data regarding solid waste management were obtained with the public authorities through interviews, document reviews and direct observations. The results demonstrate the lack of technical capacity of municipal public administration, the absence of public policies related to solid waste and lack of awareness of the population, that does not separate the recyclable waste at source, in addition, the municipality does not have a composting plant, the existing recycling center has been operated inadequately and the situation of the area of final disposal of municipal solid waste is precarious.
\end{abstract}

Key-words: municipal solid waste; solid waste management; urban sanitation

\author{
Aline Pimentel Gomes* \\ Engenheira Civil e Mestre em Engenharia pela Universidade de Passo Fundo. \\ Adalberto Pandolfo \\ Engenheiro Civil. Doutor em Engenharia de Produção. Professor da Universidade de Passo Fundo. \\ Aline Ferrão Custódio Passini \\ Engenheira de Alimentos. Doutora em Engenharia Química. Professora da Universidade de Passo Fundo. \\ Pedro Domingos Marques Prietto \\ Engenheiro Civil. Doutor em Engenharia. Professor da Universidade de Passo Fundo. \\ Nicole Becker Portela \\ Graduanda em Engenharia Ambiental pela Universidade de Passo Fundo. \\ *Endereço para correspondência: \\ Rua Gal Nascimento Vargas, 114/13 - Centro - Passo Fundo - RS - CEP: 99020-000 - Brasil e-mail: alinegomes1977@hotmail.com
}




\section{Introdução}

De acordo com Vilhena (2010), os resíduos sólidos gerados em residências (resíduos residenciais), em estabelecimentos comerciais (resíduos comerciais) e nas atividades de limpeza de ruas, capinação, poda (resíduos públicos) são denominados Resíduos Sólidos Urbanos (RSU) e são de responsabilidade da Prefeitura Municipal. Os Resíduos Sólidos Domiciliares (RSD) são constituídos pelos resíduos residenciais e comerciais.

Nos últimos anos, a quantidade, o volume e a composição dos RSU têm alterado bastante, isso se deve, principalmente, ao aumento populacional, às mudanças nos estilos de vida das pessoas e ao desenvolvimento e consumo de produtos com materiais que são menos biodegradáveis (ASASE et al., 2009).

Diariamente milhares de toneladas de RSU são geradas em todo o mundo causando diversos problemas ambientais, como poluição do ar, do solo e da água, problemas de saúde pública, como risco de transmissão de doenças e proliferação de vetores, e problemas sociais, como poluição visual e atração de catadores que trabalham em condições precárias, entre outros. Estes problemas são causados, principalmente, pela disposição final inadequada destes resíduos. A Pesquisa Nacional de Saneamento Básico 2008 revelou que, no país, 50,8\% dos municípios ainda utilizam lixões a céu aberto, $22,5 \%$ utilizam aterros controlados e $27,7 \%$ utilizam aterros sanitários para a disposição final dos RSU (IBGE, 2010).

O gerenciamento dos RSU está entre as atividades do saneamento ambiental municipal, cujo objetivo principal é propiciar a melhoria ou a manutenção da saúde da população, isto é, seu bem-estar físico, social e mental (BORGES, 2003). Este gerenciamento representa uma das maiores preocupações e fontes de despesas para os cofres públicos, por ser uma tarefa complexa devido ao crescimento da quantidade e complexidade dos resíduos gerados, a limitações de ordem financeira, falta de capacitação técnica, descontinuidade política e administrativa, ausência de controle ambiental, além da falta de conscientização da população.

Para Tchobanoglous et al. (2002), o gerenciamento dos RSU é um processo complexo que envolve um conhecimento multidisciplinar e das tecnologias existentes para controle de geração, acondicionamento, coleta, transferência, transporte, tratamento e disposição final dos resíduos. Todo o processo deve estar de acordo com a legislação existente, com os recursos financeiros disponíveis e com os aspectos de proteção ao meio ambiente e à saúde pública.

A cidade de Passo Fundo não se diferencia da maioria das cidades de médio porte brasileiras. $\mathrm{O}$ crescimento da população nos últimos anos teve como consequência o aumento da geração de resíduos, o que justifica a preocupação cada vez maior com a preservação do meio ambiente, com a saúde pública e a qualidade de vida da população. Dessa forma, torna-se necessária a busca de soluções para a questão dos RSU que melhorem a qualidade do meio ambiente urbano.

O presente trabalho tem como objetivo diagnosticar o atual sistema de gerenciamento dos RSU do município de Passo Fundo/ RS.

\section{Metodologia}

O município de Passo Fundo está localizado na região Norte do estado do Rio Grande do Sul, possui uma população total de 184.826 habitantes, sendo que 180.120 habitantes moram na área urbana, densidade demográfica de 235,92 hab $/ \mathrm{km}^{2}$ e PIB per capta de R $19.887,14$ (IBGE, 2011), tem grande importância na região, atraindo anualmente milhares de pessoas em busca de recursos nas áreas de saúde, educação, prestação de serviços, emprego e moradia e sediando diversos eventos artísticos, culturais e científicos.

A estrutura metodológica para o desenvolvimento deste trabalho foi dividida em 6 etapas, descritas a seguir:

\section{Etapa 1: Estrutura administrativa}

Nesta etapa foi identificada a estrutura administrativa da Prefeitura Municipal de Passo Fundo responsável pela limpeza urbana e manejo dos RSU gerados no município. Foram realizadas entrevistas nos meses de abril e novembro de 2010 com os responsáveis pelos Núcleos de Resíduos Sólidos, de Educação Ambiental e de Plantas da Secretaria do Meio Ambiente (SMAM) e Núcleo de Limpeza Urbana da Secretaria de Transportes e Serviços Gerais (SETRANS).

\section{Etapa 2: Geração}

Nesta etapa foram coletadas informações sobre a quantidade dos RSU gerados no município. Para isto, foram realizadas entrevistas com os responsáveis pelos Núcleos de Resíduos Sólidos e de Plantas (da SMAM) e de Limpeza Urbana (da SETRANS) e foram analisadas planilhas quantitativas referentes 
aos resíduos coletados. Quanto à determinação da composição gravimétrica destes resíduos, foram realizadas pesquisas bibliográficas sobre trabalhos já publicados sobre este assunto.

\section{Etapa 3: Acondicionamento}

Para a identificação das formas de acondicionamento dos RSU gerados no município foram realizadas visitas a alguns locais utilizados para este fim pela população, nos diversos bairros da cidade, nos meses de maio e novembro de 2010. A observação direta auxiliada pelo registro fotográfico serviu para identificar os locais e tipos de recipientes mais utilizados pela população.

\section{Etapa 4: Coleta e transporte}

Nesta etapa foram identificados os agentes formais que realizam a coleta e o transporte dos RSD, assim como os veículos utilizados para esse fim. Também foram determinadas a abrangência, a regularidade e a frequência de coleta. Com relação aos resíduos públicos, foram determinados os agentes, equipamentos e veículos utilizados para a coleta e transporte. Foram realizadas entrevistas com os responsáveis por estes serviços nos Núcleos de Resíduos Sólidos e de Plantas (da SMAM) e de Limpeza Urbana (da SETRANS) e análises dos contratos de prestação de serviços por empresas terceirizadas.

\section{Etapa 5: Tratamento e disposição final}

Por meio de entrevista com o coordenador do Nú- cleo de Resíduos Sólidos (da SMAM), foram identificadas as formas de tratamento e disposição final dos RSU coletados no município. Nesta fase, também foi realizada a descrição da situação da área de disposição de RSU do município, baseada na análise de documentos e visitas técnicas ao local nos meses de junho, julho e novembro de 2010, nas quais foram realizados registros fotográficos para melhor visualização das informações.

\section{Etapa 6: Custos operacionais}

Para a obtenção dos custos operacionais referentes aos serviços de limpeza urbana e manejo dos RSU, foram entrevistados os responsáveis pelos Núcleos de Resíduos Sólidos (da SMAM) e de Limpeza Urbana (da SETRANS) e analisados os contratos de prestação de serviços por empresas terceirizadas. Também foram analisadas leis municipais referentes à Taxa de Coleta de Lixo e consultados funcionários da Secretaria de Finanças da Prefeitura no mês de novembro de 2010.

\section{Resultados e discussão}

\subsection{Estrutura administrativa}

A estrutura administrativa da Prefeitura Municipal de Passo Fundo, responsável pela limpeza urbana e manejo dos RSU gerados no município, pode ser vista no organograma da Figura 1.

O Núcleo de Limpeza Urbana da Coordenadoria de Serviços Gerais da SETRANS tem as seguintes

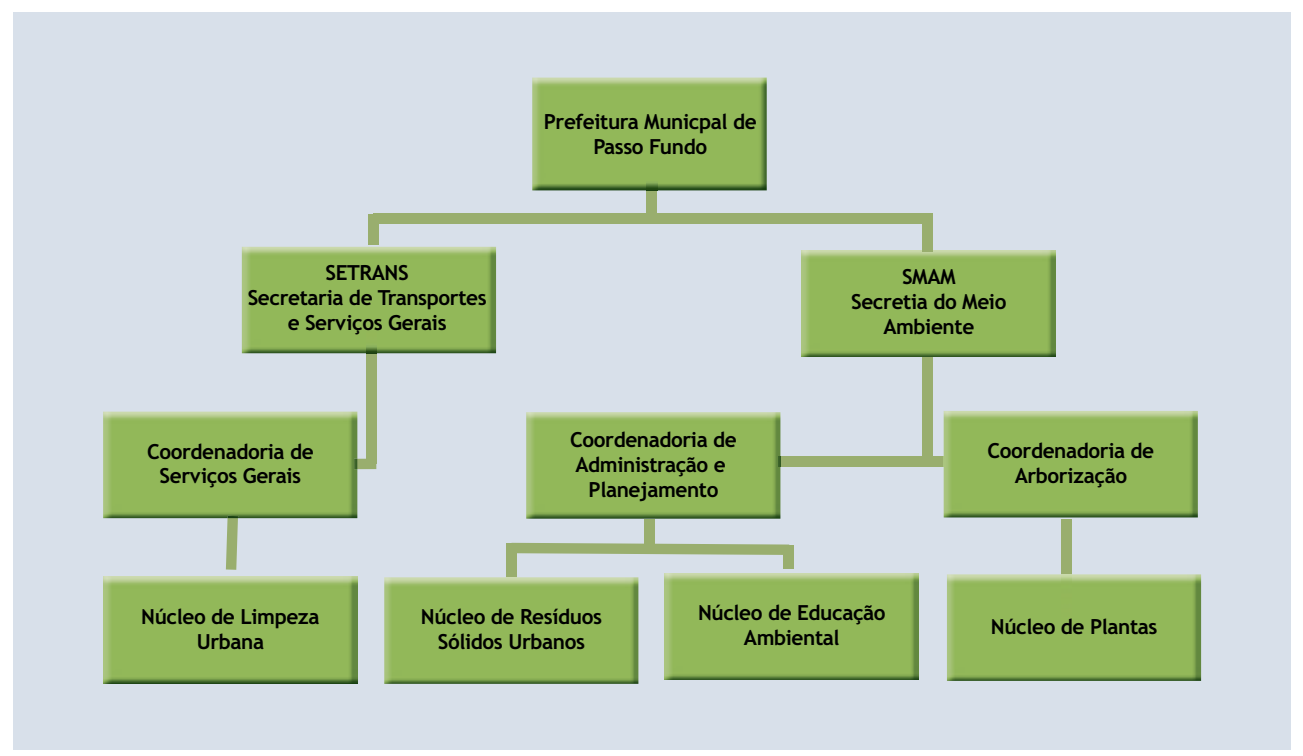

Figura 1: Organograma da estrutura administrativa responsável pela limpeza urbana e manejo dos RSU de Passo Fundo 
atribuições: limpeza das vias públicas; limpeza, manutenção e administração das praças, parques e jardins; administração de cemitérios públicos e capelas mortuárias; e limpeza de pátios das escolas e creches municipais. Possui uma equipe de funcionários que realiza serviços gerais de limpeza, que também são prestados por empresas terceirizadas.

O Núcleo de Resíduos Sólidos Urbanos da Coordenadoria de Administração e Planejamento da SMAM tem como atribuição coletar o lixo urbano e rural. É constituído por um funcionário, sem formação técnica na área de resíduos sólidos.

Cabe ao Núcleo de Educação Ambiental coordenar campanhas, eventos, palestras, cursos e programas de educação ambiental; organizar e administrar uma biblioteca com livros e materiais relativos ao meio ambiente; desenvolver projetos que busquem recursos em âmbito federal, estadual e municipal; e promover a educação ambiental em estabelecimentos de ensino público, privado, empresas e entidades. Este núcleo é constituído por um funcionário, com formação na área de educação.

No Núcleo de Plantas da Coordenadoria de Arborização existe uma equipe de funcionários, coorde- nada por um engenheiro agrônomo, que tem como atribuição a realização de serviços de podas de formação e limpeza nas árvores das vias públicas, praças e parques.

Além da estrutura administrativa da Prefeitura, existe o Conselho Municipal do Meio Ambiente, que tem caráter consultivo, deliberativo e normativo e é composto por 18 entidades governamentais e não governamentais. Este conselho foi concebido para possibilitar que os interesses coletivos da sociedade integrem a agenda pública, participando efetivamente da gestão das políticas públicas referentes ao meio ambiente.

\subsection{Geração}

As quantidades, em massa (toneladas), dos RSD coletados no município nos anos de 2006 a 2010 podem ser vistas na Tabela 1. A média mensal dos RSD coletados por ano tem apresentado um crescimento de, aproximadamente, 5,5\% ao ano.

De acordo com Kalil (2008), nos anos de 2006 e 2007, além destas quantidades, foram coletadas anualmente cerca de 130 t de resíduos recicláveis, através da coleta seletiva. A partir de 2008, este va-

\begin{tabular}{|c|c|c|c|c|c|}
\hline & 2006 & 2007 & 2008 & 2009 & 2010 \\
\hline Janeiro & $3.025,70$ & $3.382,85$ & $3.159,02$ & $3.332,60$ & $3.563,04$ \\
\hline Fevereiro & $2.378,29$ & $2.670,70$ & $3.032,32$ & $2.606,20$ & $3.033,92$ \\
\hline Março & $2.984,53$ & $2.886,28$ & $3.095,30$ & $3.110,07$ & $3.347,57$ \\
\hline Abril & $2.363,08$ & $2.752,69$ & $3.218,81$ & $3.150,44$ & $3.249,06$ \\
\hline Maio & $2.836,94$ & $3.006,75$ & $3.287,00$ & $3.156,87$ & $3.223,30$ \\
\hline Junho & $2.844,25$ & $2.896,71$ & $3.360,08$ & $3.157,00$ & $3.388,08$ \\
\hline Julho & $2.846,31$ & $2.920,05$ & $3.390,50$ & $3.224,27$ & $3.450,84$ \\
\hline Agosto & $2.902,33$ & $2.944,81$ & $3.382,55$ & $3.394,58$ & $3.376,72$ \\
\hline Setembro & $2.759,85$ & $2.875,06$ & $3.163,31$ & $3.416,44$ & $3.269,37$ \\
\hline Outubro & $3.111,65$ & $3.128,25$ & $3.301,63$ & $3.505,44$ & $3.768,39$ \\
\hline Novembro & $2.833,08$ & * & $3.121,70$ & $3.483,27$ & $3.837,38$ \\
\hline Dezembro & $3.176,44$ & * & $3.332,60$ & $3.892,74$ & $4.377,08$ \\
\hline TOTAL & $34.062,45$ & $29.464,15$ & $38.844,82$ & $39.429,92$ & $41.884,75$ \\
\hline MÉDIA & $2.838,54$ & $2.946,42$ & $3.237,07$ & $3.285,83$ & $3.490,40$ \\
\hline
\end{tabular}

Tabela 1: Quantidades (em toneladas) dos RSD coletados em Passo Fundo nos anos de 2006 a 2010 


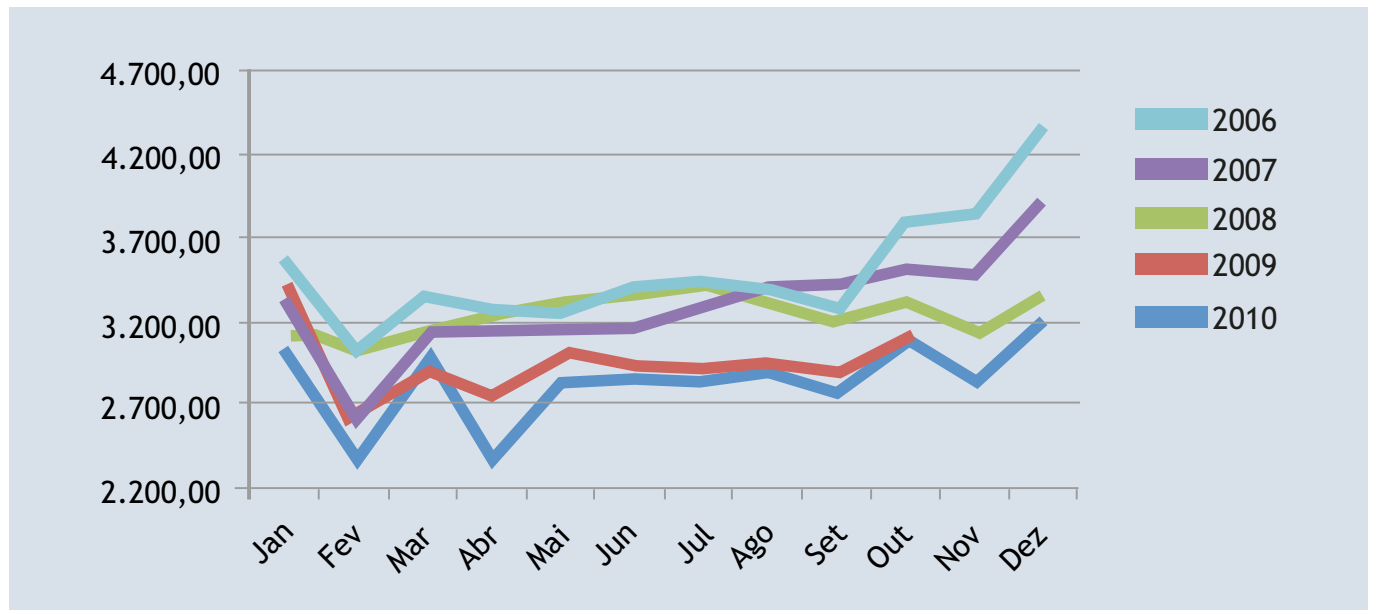

Figura 2: Quantidades (em toneladas) dos RSD coletados em Passo Fundo nos anos de 2006 a 2010

lor subiu para, aproximadamente, $400 \mathrm{t}$ por ano.

Tomando-se por base os valores de 2010, a quantidade de RSD coletados, considerando a coleta regular e seletiva, foi de 0,65 kg/habitante/dia. De acordo com o Panorama dos Resíduos Sólidos no Brasil, na região Sul são coletados 0,63 kg/habitante/dia de resíduos sólidos urbanos (ABRELPE, 2010).

A Figura 2 também apresenta as quantidades mensais dos RSD coletados no município nos anos de 2006 a 2010. Percebe-se que o mês de dezembro apresenta as maiores quantidades coletadas, pois neste mês ocorre aumento no consumo de produtos devido às festas de final de ano. Nota-se também que fevereiro apresenta as menores quantidades, por ser o mês mais curto do ano, com apenas 28 ou 29 dias, e por ser um período de férias, no qual muitas pessoas saem da cidade.

Não foram quantificados os resíduos sólidos públicos decorrentes de limpeza de vias públicas, praças, canteiros, passeios públicos, cemitérios, capelas, escolas e parques, com a execução de capina, varrição manual e mecanizada e recolhimento de entulhos e animais mortos. Nas árvores das vias públicas, praças e parques são realizados serviços de podas de formação e limpeza, gerando mensalmente cerca de $80 \mathrm{~m}^{3}$ de resíduos.

Com relação à composição gravimétrica dos RSU gerados no município, atualmente não existem dados oficiais na Prefeitura. Andrade e Rojas (2007) realizaram uma pesquisa durante os meses de maio de 2006 a abril de 2007 para determinar a composição gravimétrica dos RSD coletados no município. As amostras provenientes de 10 bairros da cidade foram recolhidas no pátio da usina de triagem do município logo após o descarregamento dos resíduos. Foram retiradas 4 amostras de $30 \mathrm{~kg}$ de diferentes locais do monte de resíduos para cada um dos 10 bairros do estudo. Posteriormente as amostras foram homogeneizadas e separou-se apenas uma de $30 \mathrm{~kg}$, que foi separada e classificada conforme a NBR 10007. Os resultados podem ser vistos na Figura 3.

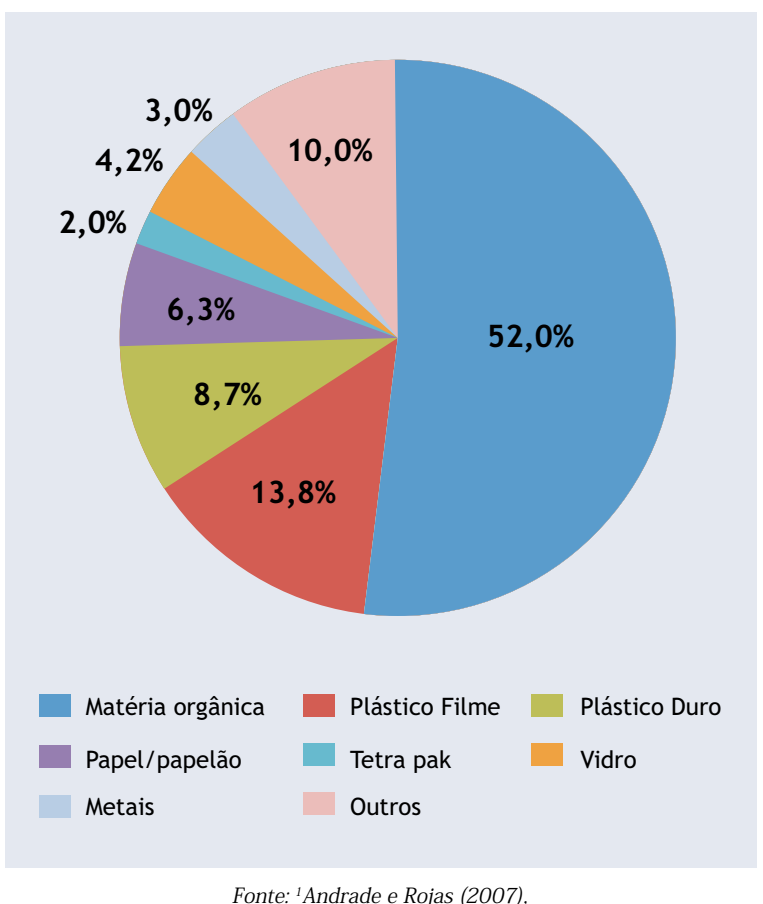

Figura 3: Composição gravimétrica dos RSD coletados em Passo Fundo 


\begin{tabular}{c|c|c|c|c|c} 
& Passo Fundo & São Carlos & Maringá & Rio Janeiro & São Paulo $^{5}$ \\
\hline Matéria orgânica & 52 & 63,68 & 52,15 & 61 & 60,74 \\
\hline Papel/papelão & 8,3 & 3,46 & 17,65 & 11 & 13,51 \\
\hline Plástico & 22,5 & 6,04 & 13,48 & 15 & 15,34 \\
\hline Metal & 3 & 1,76 & 5,01 & 2 & 1,65 \\
\hline Vidro & 4,2 & 1,56 & 3,12 & 1 & 3,24 \\
\hline Outros & 10 & 23,5 & 8,59 & 10 & 5,52
\end{tabular}

Fonte: ${ }^{1}$ Andrade e Rojas (2007), ${ }^{2}$ Lopes (2003), ${ }^{3}$ Barros Júnior (2002), ${ }^{4}$ COMLURB (2005), ${ }^{5}$ Ruberg e Serra (2007)

Tabela 2: Composição Gravimétrica (\%) dos RSD coletados em cidades brasileiras

Pode-se observar a predominância de matéria orgânica, com uma média de $52 \%$ do total de resíduos coletados, sendo que, entre os demais materiais, destaca-se ainda o plástico filme com aproximadamente $14 \%$.

A Tabela 2 apresenta a composição gravimétrica dos resíduos sólidos domiciliares coletados em algumas cidades brasileiras, com base em estudos publicados.

\subsection{Acondicionamento}

A maioria da população não faz a separação dos recicláveis na fonte. Os resíduos residenciais são acondicionados pela população em sacos de lixo e sacolas plásticas de supermercado e posteriormente dispostos de diversas maneiras, para serem coletados pela empresa contratada para os serviços de coleta e também pelos catadores de materiais recicláveis. As formas de acondicionamento mais usuais na cidade são os recipientes do tipo cesto metálico e caixa metálica e a deposição no passeio público, que podem ser vistos na Figura 4.

Na parte central da cidade, geralmente não existem recipientes para os resíduos comerciais, que são dispostos nos canteiros centrais ou nos passeios públicos, obstruindo a passagem de pedestres e ocasionando poluição visual (Figura 5).

Quanto aos pequenos resíduos descartados por pedestres em trânsito nas ruas, são utilizadas lixeiras públicas instaladas na parte central da cidade, nas ruas, avenidas, praças e parques, sendo que as mais usuais são as mostradas na Figura 6.

A maioria das lixeiras está bastante danificada e nas áreas onde ocorre maior concentração de pedestres, como nas paradas de ônibus, há acúmulo de resíduos nestes recipientes. Geralmente são encontradas nos passeios públicos na parte central da cidade e não existem ou existem em quantidade in-

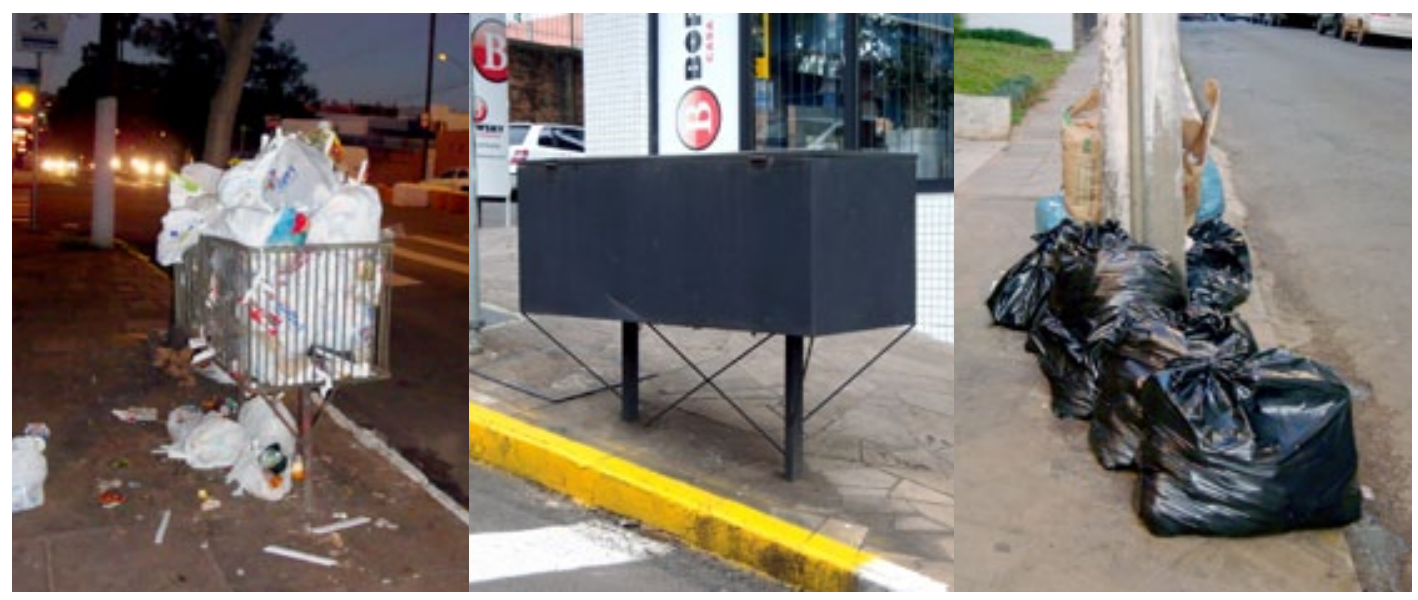

Figura 4: Formas de acondicionamento de resíduos residenciais mais utilizadas na cidade 


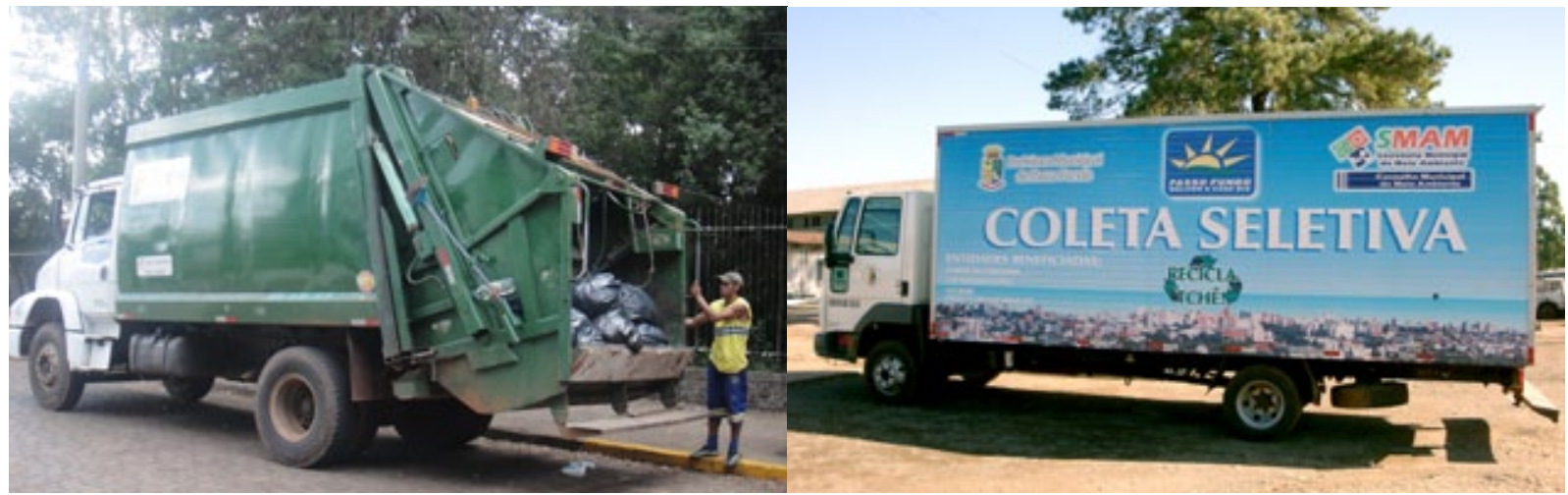

Figura 8: Veículos utilizados na coleta dos RSD de Passo Fundo

RSD podem ser vistos na Figura 8.

$\mathrm{Na}$ parte central da cidade, onde os contêineres estão sendo distribuídos, os serviços de coleta e transporte serão realizados por 2 caminhões compactadores com braços mecânicos para elevar e despejar os contêineres, 1 para a coleta dos resíduos orgânicos e outro para os recicláveis.

Destaca-se que como a população ainda não foi devidamente instruída sobre a coleta seletiva, uma grande quantidade de resíduos orgânicos tem sido depositada nos contêineres para recicláveis. Os materiais coletados nos contêineres para lixo reciclável deveriam ser encaminhados para as organizações de catadores da cidade, porém, como os resíduos não são separados pela população, estão sendo transportados para a usina de triagem do município.

Quanto aos resíduos domiciliares especiais, a Prefeitura não oferece à população a coleta de lâmpadas fluorescentes usadas, e resíduos com grandes volumes, como móveis e eletrodomésticos por exemplo. Os pneus usados coletados no município são acondicionados em um depósito localizado no Distrito Industrial, chamado de Ecoponto. Estes pneus são transportados para o município de Nova Santa Rita/ RS para um depósito da Associação Nacional da Indústria de Pneumáticos, sendo posteriormente transportados para Candiota/RS, para serem queimados em fornos para a fabricação de cimento.

Quanto aos resíduos públicos, são utilizadas roçadeiras e carros lutocar, equipados com vassouras, rastéis e pás, para a realização dos serviços de limpeza de vias, passeios públicos, praças, canteiros e parques. Os serviços de varrição mecanizada de ruas e avenidas são realizados a noite com a utili- zação de uma varredeira mecânica acoplada a um trator. E os serviços de podas de árvores em vias públicas, praças, canteiros e parques são realizados com a utilização de um caminhão equipado com triturador de galhos, motosserras e motopodadoras.

\subsection{Tratamento e disposição final}

Os resíduos sólidos domiciliares e os públicos gerados no município, decorrentes de limpeza de vias públicas, praças, canteiros, jardins, passeios públicos, cemitérios, capelas, escolas e parques, com a execução de capina, varrição manual e mecanizada e recolhimento de entulhos e animais mortos, são transportados para a área de disposição final de RSU do município. Enquanto que os resíduos públicos decorrentes de podas são coletados e transportados para o viveiro de mudas municipal e para propriedades particulares para serem compostados.

A área de disposição final de RSU do município localiza-se no bairro São João da Bela Vista e possui aproximadamente 3,5 hectares. Os RSU gerados no município têm sido dispostos neste local desde o ano de 1991. A área é composta por quatro células: no local do antigo lixão (célula A) não existem camadas de impermeabilização na base e sistema de drenagem de líquidos e gases; na área do aterro controlado (célula B) também não existem camadas de impermeabilização na base do aterro e, embora exista sistema de drenagem de líquidos e gases, este é ineficiente; as duas células de aterro sanitário (células $\mathrm{C}$ e D) foram construídas atendendo aos requisitos necessários à implantação e operação deste tipo de atividade, com camadas de impermeabilização na base e nas laterais, sistemas de drenagem de gases e coleta e transporte de lixiviado para lagoas facultativas. Destaca-se que estas duas células de 


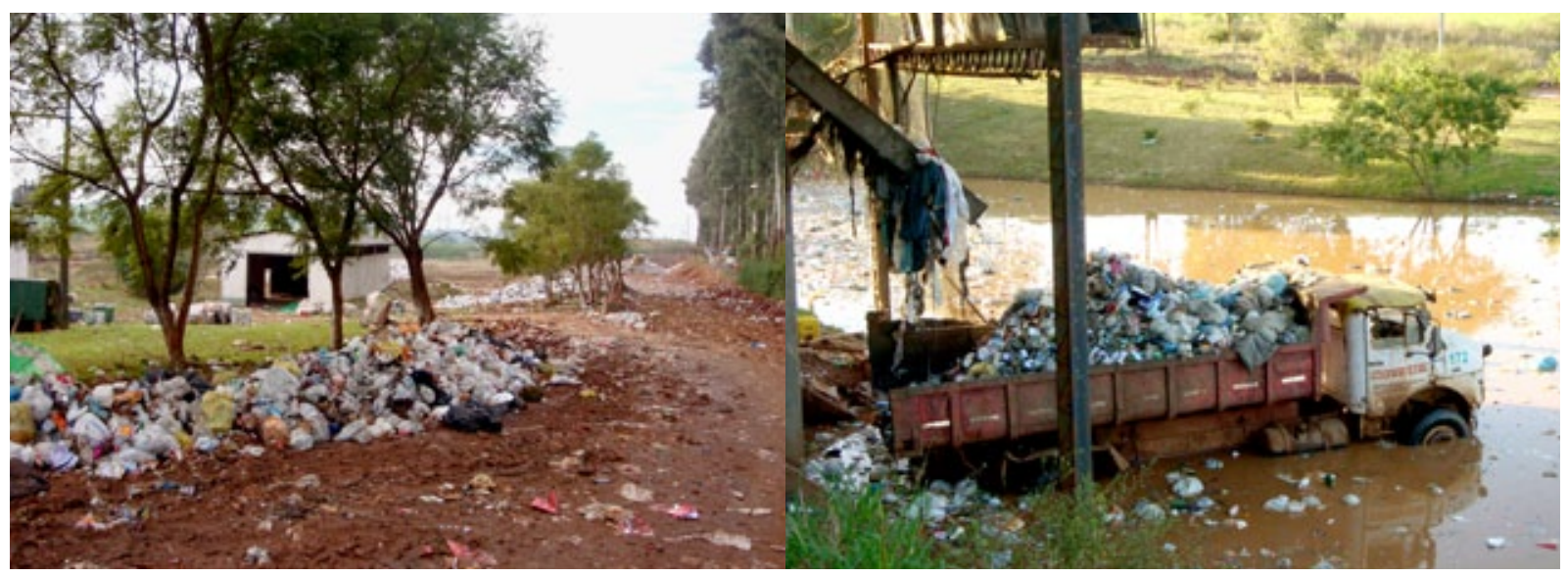

Figura 9: Estradas internas na área de disposição final de RSU do município

aterro sanitário nunca tiveram Licença de Operação da Fundação Estadual de Proteção Ambiental (FEPAM) e foram autorizadas pela mesma em caráter excepcional e emergencial através de um acordo judicial até que a área de disposição final de RSU fosse recuperada e o novo aterro sanitário fosse construído.

A área de disposição final de RSU do município é cercada e existem no local: uma guarita junto ao portão de acesso; uma balança para a pesagem dos RSD; um prédio de alvenaria onde funcionam banheiros, vestiários, refeitório, escritório e acomodações do vigia; uma garagem em alvenaria para os equipamentos utilizados no local; uma área coberta para o descarregamento dos resíduos; um prédio de alvenaria onde funciona a usina de triagem, equipada com esteira e prensas; um prédio de alvenaria para depósito dos recicláveis; 4 células de aterra- mento de resíduos; 3 lagoas para armazenamento e tratamento de lixiviado.

Desde o início de junho de 2010, a usina de triagem de materiais recicláveis está sendo operada por uma associação de catadores. De maneira geral, estes equipamentos estavam em péssimo estado, necessitando de manutenção e reparos. Nos meses seguintes, a associação de catadores teve que suspender suas atividades por inúmeras vezes, para que a esteira pudesse ser consertada e a instalação elétrica substituída com urgência, pois apresentavam risco à saúde dos trabalhadores e a iluminação era insuficiente. Estes problemas geraram uma grande desmotivação no grupo reduzindo o número de associados de 60 para 20.

Após o processo de triagem, durante os meses de junho a dezembro, os rejeitos foram depositados em uma área provisória próxima à usina de tria-

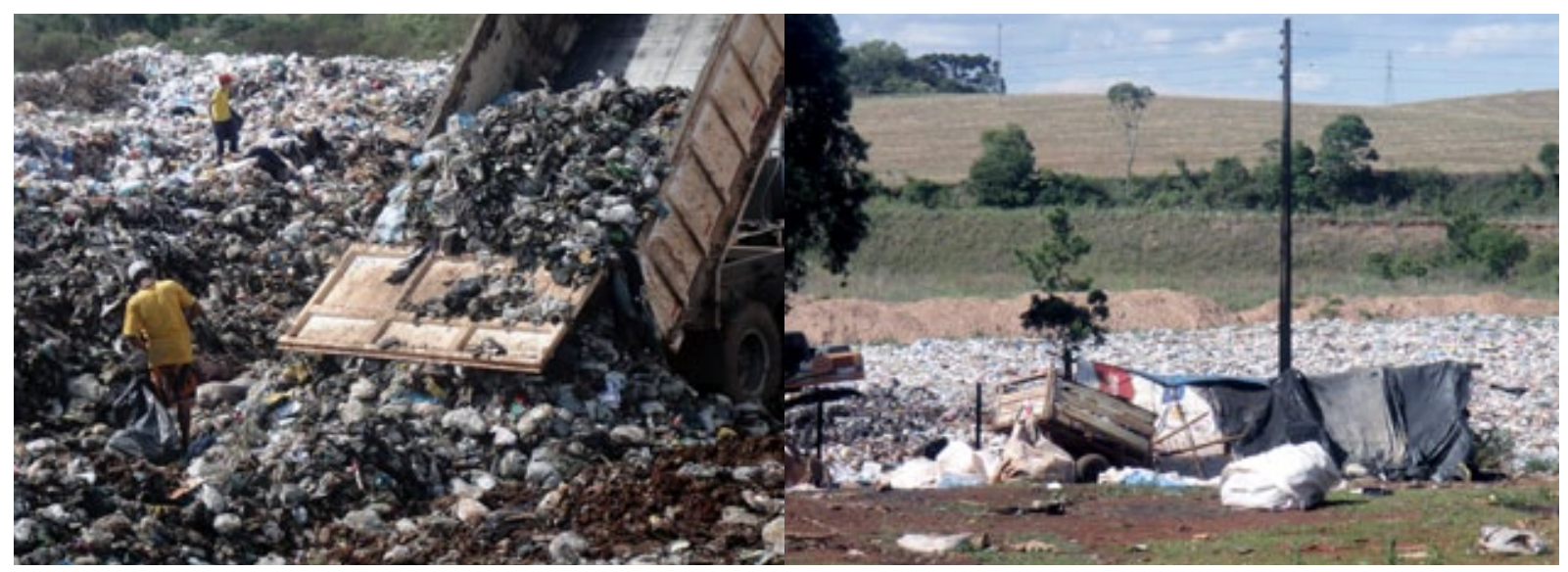

Figura 10: Catadores na área de disposição final de RSU do município 
gem, sem medidas de proteção ao meio ambiente e à saúde pública. A célula $\mathrm{D}$, que já estava encerrada desde maio de 2010 e ainda não tinha recebido a cobertura final de terra, teve que ser ampliada em novembro para receber os resíduos da área de disposição temporária por determinação judicial.

As estradas internas se encontram em péssimo estado, não são pavimentadas e em dias de chuva a maioria fica intransitável, existe grande quantidade de resíduos depositados nas áreas de circulação, o sistema de drenagem superficial é inadequado e quando chove bastante no município algumas áreas ficam alagadas (Figura 9).

Catadores realizam a catação de recicláveis na área de disposição final de RSU, alguns moram sobre as células já encerradas, próximas à usina de triagem e constroem seus barracos com materiais encontrados em meio aos resíduos e até mesmo com pedaços de geomembrana retirada da lagoa de tratamento de lixiviado (Figura 10).

Salienta-se que não é realizado nenhum tipo de monitoramento na área de disposição final de RSU do município. Além disso, existe uma grande quantidade de animais como aves, cães, gatos e cavalos.
A empresa terceirizada contratada para a operação do aterro tem prestado os serviços de forma inadequada. Desde 2005, logo depois de ter sido contratada, tem recebido dezenas de notificações por parte da SMAM por não cumprir as exigências contratuais.

\subsection{Custos operacionais}

A Tabela 3 apresenta os custos mensais referentes aos serviços de coleta, transporte e disposição final dos resíduos sólidos urbanos e serviços de limpeza urbana realizados no município por empresas terceirizadas.

Os serviços terceirizados de limpeza urbana e de coleta, transporte e disposição final dos resíduos sólidos urbanos custam mensalmente ao poder público municipal, aproximadamente, $\mathrm{R} \$ 650.000,00$, o que corresponde a um custo de $\mathrm{R} \$ 3,60$ habitante/mês. Considerando-se somente os serviços terceirizados referentes à coleta, transporte e disposição final dos RSU, o custo mensal é de, aproximadamente, $\mathrm{R} \$ 470.000,00$, sendo de $\mathrm{R} \$ 2,60$ habitante/mês. De acordo com ABRELPE (2010), as despesas municipais mensais com coleta de re-

\begin{tabular}{l|c|c|c|c}
\hline Serviço Contratado & Unidade & Valor Unit. & Quantidade & Valor \\
\hline Coleta seletiva de recicláveis (caminhão baú) & Km rodado & 4,97 & $2.260,00^{*}$ & $11.232,20$ \\
\hline Coleta seletiva de recicláveis (cam. compact.) & Km rodado & 9,88 & $2.100,00^{*}$ & $20.748,00$ \\
\hline Coleta de resíduos domiciliares e comerciais & tonelada & 84,00 & $3.490,40^{*}$ & $293.193,60$ \\
\hline Operação do aterro sanitário & Preço global & - & - & $68.707,36$ \\
\hline Recolhimento de animais mortos & Km rodado & 2,34 & $2.500,00^{* *}$ & $5.850,00$ \\
\hline $\begin{array}{l}\text { Varrição mecanizada de ruas e avenidas } \\
\text { Serviços gerais em ruas, passeios públicos, } \\
\text { praças, cemitérios, capelas, escolas e parques }\end{array}$ & Preço global & - & - & $24.099,65$ \\
\hline $\begin{array}{l}\text { Limpeza de ruas, com capina e varrição, podas } \\
\text { e recolhimento de entulhos }\end{array}$ & Preço global & - & - & $81.921,00$ \\
\hline Locação de contêineres e papeleiras & litro & 0,11 & 601.000 & $66.110,00$ \\
\hline $\begin{array}{l}\text { Construção de célula do aterro sanitário } \\
\text { TOTAL MENSAL }\end{array}$ & Preço global & - & & $11.000,00$ \\
\hline
\end{tabular}

Tabela 3: Custos mensais dos serviços terceirizados de limpeza urbana e manejo dos RSU 
síduos sólidos urbanos no Brasil e na região Sul são de $\mathrm{R}$ \$ 3,41 habitante/mês e R \$ 3,00 habitante/mês, respectivamente.

A Taxa de Coleta de Lixo (TCL) foi instituída no município pela Lei Municipal $n^{\circ} 1.779$ de 1977. Foi cobrada durante alguns anos e posteriormente cancelada. Em novembro de 2009 a TCL passou a vigorar novamente com alterações introduzidas pela Lei Complementar $n^{\circ} 233$, tendo como fato gerador a utilização, efetiva ou potencial, dos serviços de coleta, remoção, transporte e condicionamento final de lixo, domiciliar ou não, prestados ao contribuinte ou postos à sua disposição. É estipulada a partir de critérios de periodicidade de recolhimento e tipo de estabelecimento gerador de resíduos (PASSO FUNDO, 2009).

A cobrança da TCL teve início no mês de setembro de 2010, mediante inserção nas contas de consumo mensal de energia elétrica a partir de um convênio entre o Executivo Municipal e a concessionária de energia elétrica (RGE). O valor mensal arrecadado é de aproximadamente $\mathrm{R} \$ 200.000,00$.

Observa-se que este valor está abaixo do custo mensal dos serviços terceirizados referentes à coleta, transporte e disposição final dos resíduos sólidos urbanos que é de, aproximadamente, $\mathrm{R} \$$ 470.000,00.

\section{Conclusões}

A Prefeitura dispõe de uma estrutura administrativa inadequada devido à falta de capacitação técnica, principalmente nos Núcleos de Resíduos Sólidos e de Educação Ambiental. Apesar de alguns esforços em divulgar os programas de educação ambiental relacionados aos RSU, estes não têm conseguido atingir a totalidade da população, que tem pouca conscientização quanto aos problemas causados por estes resíduos. Outro problema é a ausência de um Plano Municipal de Gestão Integrada dos RSU e a falta de dados sobre o atual gerenciamento destes resíduos.

Como ainda não existe no município um projeto estruturado de coleta seletiva, apenas algumas iniciativas que estão sendo implementadas pelo poder público, como a distribuição de contêineres na parte central da cidade, a população não faz a segregação na fonte geradora e nem o acondicionamento adequado dos recicláveis.

Quanto às formas de tratamento dos RSU, o município não possui uma usina de compostagem, a qual poderia aproveitar a fração orgânica dos resíduos que representa mais de $50 \%$ do total coletado, e a usina de triagem existente não tem sido operada de forma adequada devido a problemas nos equipamentos e na instalação elétrica. $\mathrm{O}$ resultado disso é que toneladas de resíduos que poderiam ser reaproveitados são aterrados todos os dias, reduzindo a vida útil do aterro sanitário.

A situação da área de disposição final de RSU do município é precária, caracterizando-se como um lixão a céu aberto, sem medidas de proteção ao meio ambiente e a saúde pública, sem a cobertura diária de terra, sem monitoramento, com uma grande quantidade de resíduos espalhados nas áreas de circulação e estradas internas e a presença de catadores e muitos animais.

É importante ressaltar que a administração pública tem priorizado as metas de curto prazo, implementando procedimentos e tecnologias corretivas, ao invés de metas propostas para médio e longo prazo, que visam obter os meios técnicos e financeiros necessários para executar programas de caráter preventivo, evitando os problemas causados pelos RSU no município.

Este estudo traz contribuições ao conhecimento do atual sistema de limpeza urbana e manejo dos resíduos sólidos urbanos no município. Os dados obtidos poderão subsidiar o planejamento de políticas públicas e a elaboração do Plano Municipal de Gestão Integrada de Resíduos Sólidos Urbanos.

\section{Referências}

ABRELPE. Associação Brasileira de Empresas de Limpeza Pública e Resíduos Especiais. Panorama dos Resíduos Sólidos no Brasil 2009. 2010. 210p.

ANDRADE, A. P. de; ROJAS, J. W. J. Análise da Composição Gravimétrica para a implantação da compostagem dos RSU. Anais do II MADEHUMAN II. 2007.

ASASE, M. et al. Comparison of municipal solid waste management systems in Canada and Ghana: A case study of the cities of London, Ontario, and Kumasi, Ghana. Elsevier. Waste Management. p. 2779-2786. jul. 2009.

BARROS JÚNIOR, C. de. Os resíduos sólidos urbanos na cidade de Maringá: Um modelo de gestão. 2002. Tese (Doutorado em Engenharia Química, área de Desenvolvimento de Processos) - Universidade Estadual de Maringá - Maringá, 2002.

BORGES, J. C. de. Resíduos Sólidos Urbanos: Aterro sustentável para municípios de pequeno porte. 3 . ed. São Paulo, 2003. 
COMLURB. Companhia Municipal de Limpeza Urbana. Caracterização Gravimétrica dos Resíduos Sólidos Domiciliares do Município do Rio de Janeiro 2005. Disponível em:< http://comlurb.rio. rj.gov.br/download/caracterizacao_do_lixo_domiciliar_2005.pdf>. Acesso em: 08 jul. 2010.

IBGE - INSTITUTO BRASILEIRO DE GEOGRAFIA E ESTATISTICA. Cidades@. Disponível em: $<$ http:// www.ibge.gov.br/cidadesat/topwindow.htm?1 > Acesso em: 15 maio 2011.

IBGE - INSTITUTO BRASILEIRO DE GEOGRAFIA E ESTATISTICA. Pesquisa Nacional de Saneamento Básico 2008. Rio de Janeiro, 2010. 219p.

KALIL, R. Redes de Infraestrutura Urbana: gestão de programas e projetos na cidade de Passo Fundo de 2005 a 2007. 2008. Dissertação (Mestrado em Engenharia - área de concentração em Infraestrutura e Meio Ambiente) - Universidade de Passo Fundo - Passo Fundo, 2008.

LOPES, A. A. Estudo da gestão e do gerenciamento integrado dos resíduos sólidos urbanos no município de São Carlos/SP. 2003. Dissertação (Mestrado em Ciências da Engenharia Ambiental) - Escola de Engenharia de São Carlos da Universidade de São Paulo - São Carlos, 2003.

PASSO FUNDO. Lei Complementar $n^{\circ} 233$ de 03 de novembro de 2009. Dispõe sobre a taxa de coleta de lixo no município de Passo Fundo. Disponível em: < http://www .pmpf.rs.gov.br/index.php?p $=1145 \& \mathrm{a}=1 \& \mathrm{pm}=1 \& \mathrm{ifr}=1>$. Acesso em: 15 mar. 2010.

RUBERG, C.; SERRA, G. G. Destinação de resíduos sólidos domiciliares em megacidades: uma análise do município de São Paulo. Revista Brasileira de Ciências Ambientais. No 8. p. 4-9, dez. 2007.

TCHOBANOGLOUS, G. et al. Introduction. In: TCHOBANOGLOUS, G; KREITH, F. (co-Ed.). Handbook of solid waste management. 2. ed. New York: McGraw-Hill, 2002.

VILHENA, A. (Coord.). Lixo Municipal: Manual de Gerenciamento Integrado. 3. ed. São Paulo: Compromisso Empresarial para Reciclagem (CEMPRE), 2010. 350p.

\section{O site da revista DAE está repleto de novidades}
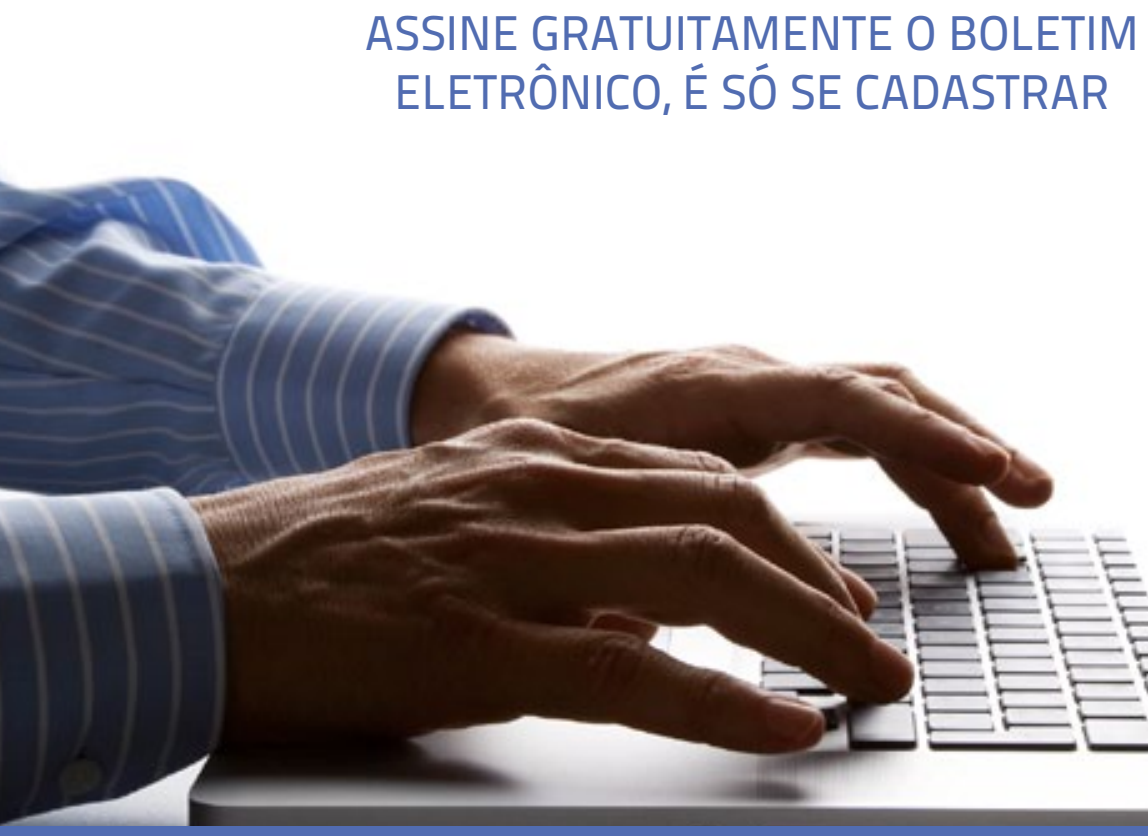